\title{
The Glutamate Uptake Inhibitor L-Trans-pyrrolidine-2,4-dicarboxylate Depresses Excitatory Synaptic Transmission via a Presynaptic Mechanism in Cultured Hippocampal Neurons
}

\author{
Reiko Maki,' Michael B. Robinson, ${ }^{1,3}$ and Marc A. Dichter ${ }^{1,2}$ \\ 'David Mahoney Institute of Neurological Sciences and 'Departments of Neurology and Pharmacology, University of \\ Pennsylvania, School of Medicine and The Graduate Hospital, and ${ }^{3}$ The Children's Seashore House, Children's Hospital \\ of Philadelphia, and Departments of Pediatrics and Pharmacology, University of Pennsylvania, Philadelphia, PA 19104
}

\begin{abstract}
Sodium-dependent high-affinity uptake of glutamate is thought to play a major role in the maintenance of very low extracellular concentrations of excitatory amino acids (EAA), and may modulate the actions of released transmitter at G-protein-coupled receptors and extrasynaptic receptors that are activated over a longer distance and time course. We have examined the effects of the recently developed uptake inhibitor L-trans-pyrrolidine-2,4-dicarboxylate (L-transPDC) on monosynaptically evoked excitatory postsynaptic currents (EPSCs) in very-low-density cultures of hippocampal neurons. L-Trans-PDC produced a decreased amplitude of both the non-NMDA and NMDA receptor-mediated components of monosynaptically evoked EPSCs. Examination of miniature EPSCs (mEPSCs) indicated that changes in the sensitivity of postsynaptic non-NMDA receptors did not underlie the decrease in evoked EPSC amplitudes. The metabotropic receptor agonist (1S,3R)-1-aminocyclopentane1,3-dicarboxylic acid (1S,3R-ACPD) also depressed both components of the EPSC. The competitive metabotropic receptor antagonist (RS)- $\alpha$-methyl-4-carboxyphenylglycine (MCPG) blocked the depression of EPSC amplitude induced by $1 S, 3 R-A C P D$ and also blocked the effects of $L$-trans-PDC. Finally, low concentrations of L-glutamate $(2 \mu \mathrm{M})$ mimicked the effects of L-trans-PDC on EPSC amplitude. From these results we conclude that the application of L-trans-PDC to cultured hippocampal neurons results in the activation of presynaptic metabotropic receptors, leading to a decrease in synaptic transmission. We propose that this effect is due to an increase in ambient glutamate concentrations following inhibition of glutamate uptake, resulting in presynaptic inhibition of excitatory synaptic transmission.
\end{abstract}

[Key words: EPSC, mEPSC, L-Trans-PDC, EAA uptake inhibition, ACPD, MCPG, tissue culture, patch clamp]

\footnotetext{
Received Jan. 7, 1994; revised Apr. 22, 1994; accepted May 5, 1994.

We thank Drs. Karen Wilcox and Louis Littman for critical review of the manuscript and advice, Ms. Kay Cherian and Ms. Margaret Price for preparation and maintenance of the tissue cultures, and Mr. J. Josh Lawrence for technical assistance. This work was supported by GM-34781 (M.A.D., M.B.R.), AG-1200301 (R.M.), NS29868 (M.B.R.), and NS24260 (M.A.D.)

Correspondence should be addressed to Marc A. Dichter, M.D., Ph.D., Department of Neurology, Graduate Hospital, 19th and Lombard Streets, Philadelphia, PA 19146

Copyright (c) 1994 Society for Neuroscience $0270-6474 / 94 / 146754-09 \$ 05.00 / 0$
}

Most previous studies on the involvement of reuptake in excitatory synaptic transmission have shown potentiated neuronal responses to exogenously applicd glutamatc (Lodge ct al., 1979, 1980; Johnston et al., 1980; Saweda et al., 1985; Brodin et al., 1988; Hestrin et al., 1990). However, the temporal and spatial characteristics of exogenous application of glutamate may be very different from synaptically released transmitter. Iontophoretically applied transmitters are not localized to the synapse, exist in nonphysiologic concentrations, and affect both synaptic and extrasynaptic receptors, and are therefore more susceptible to slow removal processes by neuronal and glial transporters.

Recent studies have addressed the effects of uptake inhibition on the time course of excitatory postsynaptic currents (EPSCs). Dihydrokainate (DHK), a glutamate uptake inhibitor, did not affect the non-NMDA component of evoked EPSCs in CA1 neurons of hippocampal slices but did increase the amplitude, but not the duration, of the NMDA receptor-mediated component (Hestrin et al., 1990). However, DHK is a weak inhibitor of glutamate uptake, and directly activates postsynaptic EAA receptors (Bridges et al., 1991; see also Results). Sarantis et al. (1993) investigated the effects of the potent and selective uptake inhibitor L-trans-pyrrolidine-2,4-dicarboxylate (L-trans-PDC) on synaptic currents in hippocampal and cerebellar slices. L-Trans-PDC at $300 \mu \mathrm{M}$ decreased the NMDA component of EPSCs, whereas the non-NMDA EPSCs were either unaffected or slightly reduced in amplitude, with no effect on the decay time constant. Isaacson and Nicoll (1993) reported that while L-trans-PDC potentiated the effects of exogenously applied glutamate in hippocampal slices, synaptically evoked EPSCs were unaffected. The time course of the EPSCs was unchanged; a small and variable decrease in the peak amplitude of the EPSC in a fraction of the cells was noted. Application of $\mathrm{L}$-trans-PDC to these hippocampal slices resulted in an elevation of the extracellular levels of glutamate. Very recently, Mennerick and Zorumski (1994) reported that inhibition of glutamate uptake by glial depolarization, $\mathrm{Li}^{+}$, or hydroxyaspartate prolonged the decay rate of non-NMDA autaptic currents in the presence of cyclothiazide (in order to block non-NMDA receptor desensitization), as well as the decay rate of NMDA autaptic currents in cultured hippocampal single-neuron microislands. To date, this is the only demonstration that inhibition of glutamate uptake may affect the time course of the postsynaptic response.

Inhibition of glutamate uptake, and the subsequent accumulation of extracellular glutamate, could have both presyn- 
aptic and postsynaptic consequences. Rapid desensitization of the quisqualate/AMPA receptors (Tang et al., 1989; Trussel and Fischbach, 1990) by ambient concentrations of glutamate could result in a decreased amplitude of the EPSC. An increase in the NMDA component of the EPSC may also be expected, given the high affinity of the NMDA receptor for glutamate (Patneau and Mayer, 1990). Conversely, accumulated glutamate could feed back onto presynaptic autoreceptors and depress EPSC amplitude (Forsythe and Clements, 1990; Baskys and Malenka, 1991; Pacelli and Kelso, 1991; Desai and Conn, 1992). In fact, inhibition of GABA uptake produces a decrease in the amplitude of GABA-mediated IPSCs between hippocampal neurons in culture by acting in an analogous manner; activation of presynaptic $\mathrm{GABA}_{B}$ receptors decreases neurotransmitter release (Oh and Dichter, 1994).

In the experiments reported here, we have examined the effects of L-trans-PDC on excitatory synaptic transmission between hippocampal neurons in very-low-density culture. L-TransPDC potently inhibits glutamate uptake in these cultures, and does not induce a sizeable inward current, unlike previously used uptake inhibitors. L-Trans-PDC significantly decreased the amplitudes of both the non-NMDA and NMDA receptor-mediated components of monosynaptically evoked EPSCs between pairs of hippocampal cells. This appeared to be due to a presynaptic mechanism, possibly due to an increased concentration of ambient glutamate feeding back onto presynaptic metabotropic glutamate receptors to decrease neurotransmitter release.

\section{Materials and Methods}

Primary hippocampal cultures. Primary dissociated cultures were prepared from embryonic rat hippocampi as described previously (Buchhalter and Dichter, 1991) with additional modifications for plating at very low density (Wilcox and Dichter, 1994).

Electrophysiological techniques. Miniature EPSCs (mEPSCs) were recorded at room temperature using the whole-cell patch-clamp technique (Hamill et al., 1981) from high-density cultured hippocampal neurons ranging from 14 to $28 \mathrm{~d}$ old. Recordings were made using patch electrodes with resistances of $2-4 \mathrm{M} \Omega$ made from borosilicate glass capillaries (Kimax). Postsynaptic currents were monitored in the whole-cell voltage-clamp configuration with seal resistances of $300 \mathrm{M} \Omega$ to $1 \mathrm{G} \Omega$ at a holding potential of $-80 \mathrm{mV}$ using a DAGAN 8900 or 3900 patchclamp amplifier.

Evoked EPSCs were recorded from monosynaptically connected pairs of hippocampal neurons maintained in very-low-density cultures. Isolated pairs of neurons were visualized using phase-contrast microscopy with a Nikon inverted microscope. A DAGAN 3900 or 8900 patchclamp amplifier was used to monitor and stimulate the presynaptic cell in the current-clamp mode; postsynaptic currents were monitored in the whole-cell voltage-clamp configuration, at a holding potential of $-80 \mathrm{mV}$. Low-frequency stimulation $(0.125 \mathrm{~Hz})$ was used to ensure relatively stable amplitudes of EPSCs.

Electrode offset potentials were compensated prior to recording with amplifier circuitry. Recordings were filtered at $5-10 \mathrm{kHz}$ using amplifier circuitry; data were digitized at $10 \mathrm{kHZ}$ by the pCLAMr data acquisition system (Axon Instrument) for subsequent analysis. Data was stored on videotape using a VR-10 digital data recorder (Instrutech) for off-line analysis.

Recording solutions. The external bath solution, a HEPES-buffered saline (HBS), contained the following (in $\mathrm{mM}$ ): $\mathrm{NaCl}, 145 ; \mathrm{KCl}, 3 ; \mathrm{HEPES}$, $10 ; \mathrm{CaCl}_{2}, 2$ or $4 ;$ glucose, 8 (pH 7.4,300-320 mOsm). For the recordings of mEPSCs, $1 \mathrm{~mm} \mathrm{MgCl}, 100 \mu \mathrm{M} \mathrm{APV}$, and $3 \mu \mathrm{M}$ tetrodotoxin (TTX) were included in the bath solutions of the experiments to block NMDA receptor-mediated activity, and to block sodium-dependent action potentials. Bicuculline at $10 \mu \mathrm{M}$ was used to block inhibitory synaptic inputs. Recordings of evoked EPSCs were done in $\mathrm{Mg}^{2+}$-free HBS and $10 \mu \mathrm{M}$ glycine (unless otherwise indicated) to allow full expression of the NMDA component of the EPSC; $4 \mathrm{mM} \mathrm{CaCl}_{2}$ was also used in the external solution to reduce the excitability of the membrane and thereby reduce the probability of spontaneous action potentials. Perfusion of the neurons with various extracellular solutions was achieved using a peristaltic pump. The antagonist MCPG was coapplied with either $1 S, 3 R-$ ACPD or L-trans-PDC by bath perfusion.

The internal solution of the whole-cell patch electrode for mEPSC recordings contained (in $\mathrm{mM}$ ) $\mathrm{CsCl}, 140$; EGTA, 2; HEPES, 10; glucose, 10; ATP- $\mathrm{Mg}^{2+}, 4$ (pH 7.4, 290-300 mOsm). For the paired recordings, $140 \mathrm{~mm} \mathrm{~K}$-gluconate was used as the major ionic constituent to allow excitatory postsynaptic currents (EPSCs) to be readily distinguished from inhibitory postsynaptic currents (IPSCs) on the basis of reversal potential; the reversal potential for IPSCs with potassium gluconate electrodes is approximately $-50 \mathrm{mV}$, whereas the reversal potential for EPSCs remains between 0 and $+10 \mathrm{mV}$.

Pharmacologic compounds used in these experiments included bicuculline methiodide $(10 \mu \mathrm{M})$, APV $(100 \mu \mathrm{M})$ (both from Sigma), CNQX $(10 \mu \mathrm{M})$ (Research Biochemicals Inc.), TTX (3 $\mu \mathrm{M})$ (Calbiochem), dihydrokainate ( $1 \mathrm{~mm}$ ) (Cambridge Research Biochemicals), D,L- $\beta$-threohydroxyaspartate $(50 \mu \mathrm{M})$ (Calbiochem), L- aspartate- $\beta$-hydroxamate $(100 \mu \mathrm{M})($ Sigma), L-trans-PDC $(100,250 \mu \mathrm{M}),(1 S, 3 R)$-1-aminocyclopentane-1,3-dicarboxylic acid (1S,3R-ACPD; $100 \mu \mathrm{M})$, and $(R S)-\alpha-$ methyl-4-carboxyphenylglycine (MCPG; $500 \mu \mathrm{M}$ ) (all from Tocris Neuramin).

$\mathrm{L}^{3}{ }^{3} \mathrm{H}$-glutamate transport assays. Inhibition of uptake of $\mathrm{L}^{-3} \mathrm{H}$-glutamate was measured as previously described (Robinson et al., 1991) with some minor modifications. Triplicate assays were performed in a final volume of $0.5 \mathrm{ml}$ of $\mathrm{HBS}$ containing $2 \mathrm{mM} \mathrm{CaCl}$ and $0 \mathrm{Mg}^{2+}$ in the presence and absence of $\mathrm{L}$-trans-PDC. In parallel assays, uptake was measured in the absence of sodium by substituting equimolar choline chloride for the $\mathrm{NaCl}$ in the HBS. All assay components were added to cultures grown in 12-well $22 \mathrm{~mm}$ culture plates (Corning). Assays were performed at room temperature and stopped after a 5 min incubation by addition of $2 \mathrm{ml}$ of cold $\left(4^{\circ} \mathrm{C}\right)$ choline-containing buffer. The cells were rinsed three times with $1 \mathrm{ml}$ of ice-cold choline-containing buffer, and then lysed with $1 \mathrm{ml}$ of $0.1 \mathrm{~N} \mathrm{NaOH}$. The radioactivity was determined by scintillation spectrometry at an efficiency of $>45 \%$. Sodiumdependent uptake was calculated to be the difference between the amount of radioactivity observed in the presence of sodium and the amount observed in the choline-containing buffer.

The $\mathrm{IC}_{30}$ value is a weighted mean value assuming a theoretical curve with a Hill coefficient of 1 .

Data analyses. Data were analyzed using pCLAMP analysis software (Axon Instruments).

Amplitudes for miniature currents were plotted on relative cumulative frequency histograms, which plot the cumulative frequency of all currents as a function of amplitude. The nonparametric KolmogorovSmirnov statistical test was then applied to various populations of minis to determine significance in the difference of amplitude distribution. Only values of $p<0.05$ were considered significant in these experiments (van der Kloot, 1991).

Unpaired Student's $t$ tests were used to determine significance of differences between populations of evoked EPSCs; paired Student's $t$ tests were applied to means of EPSC amplitude to determine significance of an overall effect. The control values used to compare the effect of a given drug were determined before each application treatment in a given cell to account for potential variability over the course of a recording. The mean amplitudes for each drug were then compared to the control mean amplitude of the EPSCs recorded immediately previous to the trial (and immediately following to determine reversibility). Values of $p<0.05$ were considered significant.

All data reported are mean $\pm S D$.

\section{Results}

Inhibition of $\mathrm{L}^{-3} \mathrm{H}$-glutamate uptake by $\mathrm{L}_{\text {-trans- }} \mathrm{PDC}$

The effect of L-trans-PDC on the sodium-dependent high-affinity transport of $\mathrm{L}^{-3} \mathrm{H}$-glutamate $(0.5 \mu \mathrm{M})$ in high-density hippocampal neuronal cultures was examined. Concentrations ranging from $10 \mu \mathrm{M}$ to $1 \mathrm{mM} \mathrm{L-trans-PDC}$ were used to determine the potency of this recently described uptake inhibitor (Bridges et al., 1991) in our culture system (Fig. 1). The $\mathrm{IC}_{50}$ value was $26 \mu \mathrm{M}$; this and other published data (Robinson et al., 1991, 1993) indicate that L-trans-PDC is one of the most potent inhibitors of glutamate uptake identified to date. The $\mathrm{IC}_{50}$ value reflects both glial and neuronal uptake in these cul- 


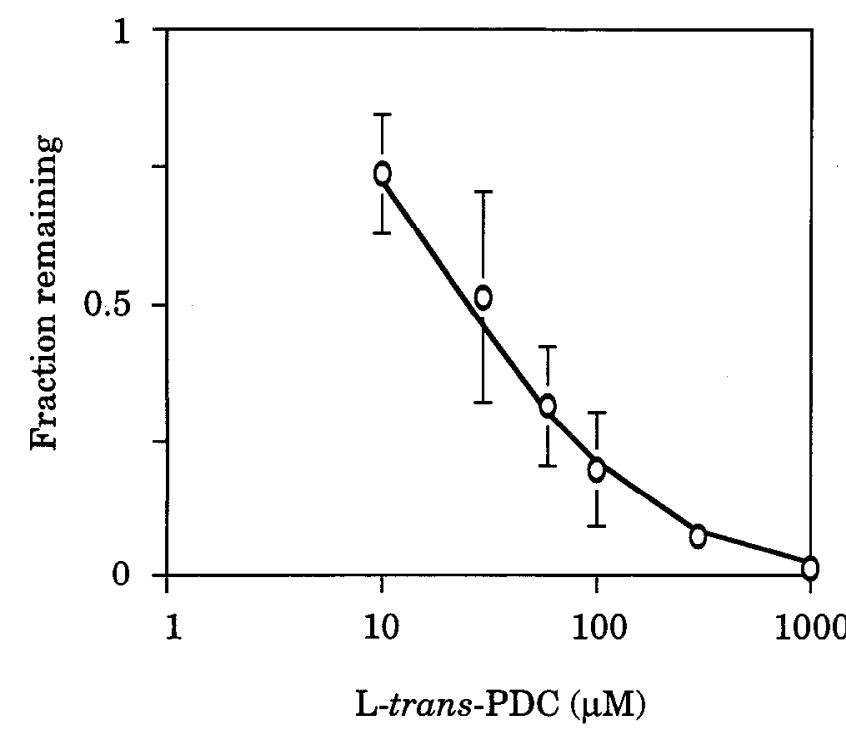

Figure 1. Uptake of $\mathrm{L}^{-3} \mathrm{H}$-glutamate $(0.5 \mu \mathrm{M})$ was measured in the absence and presence of increasing concentrations of L-trans-PDC using high-density cultured hippocampal neurons. $\mathrm{IC}_{50}$ is $26 \mu \mathrm{M}$. Data points are mean \pm SD (error bars) values from six independent observations.

tures, since the neurons grow on a confluent bed of glia. The concentrations of $\mathrm{L}$-trans-PDC used for the electrophysiological experiments were chosen to fall within the range of the $\mathrm{IC}_{50}$ for uptake inhibition in these cultures.

\section{Glutamate uptake inhibitors induce inward currents mediated by EAA receptors}

Bridges et al. (1991) have used pharmacological techniques to address whether L-trans-PDC and other uptake inhibitors directly interact with ionotropic EAA receptors. We used focal puffer application to determine electrophysiologically whether L-trans-PDC and other previously available uptake inhibitors had direct agonist actions resulting in the induction of inward currents in cultured hippocampal neurons. Focal puffer pipettes allow the rapid, quantitative replacement of extracellular media with media containing known concentrations of neurotransmitter or drug (Choi and Fischbach, 1981). Concentrations of the uptake inhibitors dihydrokainate (DHK; $1 \mathrm{~mm}$ ), L-aspartate$\beta$-hydroxamate (L-A $\beta \mathrm{H} ; 100 \mu \mathrm{M}), \mathbf{D}, \mathbf{L}-\beta$-threo-hydroxyaspartate (THA; $50 \mu \mathrm{M})$, and L-trans-PDC $(100,250 \mu \mathrm{M})$ were chosen based on two factors: (1) the concentrations are at least 10 times the $\mathrm{IC}_{50}$ for inhibition of glutamate uptake as measured in synaptosomes (Robinson et al., 1991, 1993), and (2) these are concentrations that have been used in previous experiments examining the effects of uptake inhibition in various preparations (Lodge et al., 1979, 1980; Johnston et al., 1980; Saweda et al., 1985; Brodin et al., 1988; Hestrin et al., 1990). DHK, L-A $\beta H$, and THA directly activated ionotropic EAA receptors, and induce sizable inward currents at the concentrations used (Table 1). Currents induced by these compounds could be fully blocked by $100 \mu \mathrm{M}$ APV and $10 \mu \mathrm{M}$ CNQX and were not characterized further. Moreover, the rapid onset of the inward current upon application of the compounds was comparable to the time course of the response to $100 \mu \mathrm{M}$ glutamate, indicating rapid activation of postsynaptic EAA receptors. This direct effect on the hippocampal neurons would preclude these compounds from being useful for further physiological studies.

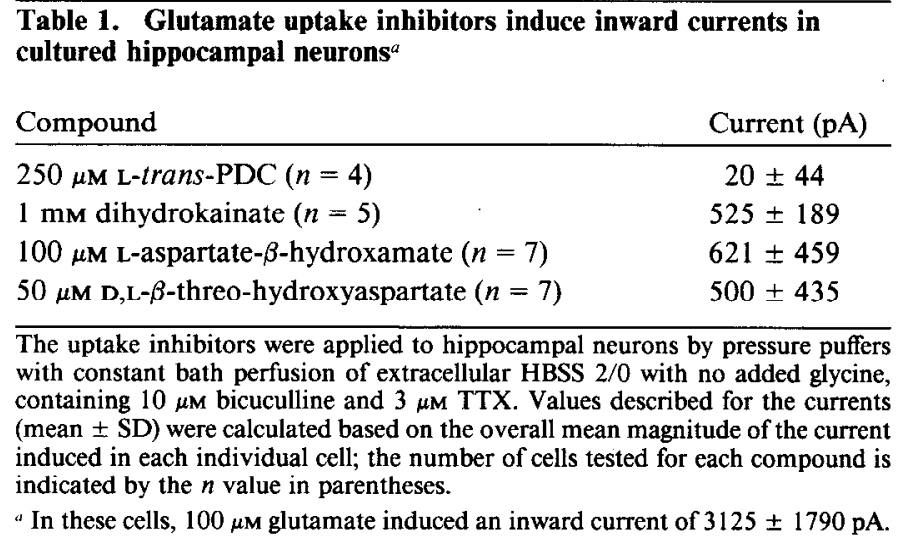

At very high ( $>1 \mathrm{~mm}$ ) concentrations, $\mathrm{L}$-trans-PDC induced a similar rapid onset inward current. However, at the concentrations used for the following experiments (100 and $250 \mu \mathrm{M}$ ), L-trans-PDC did not induce any substantial current: a small inward shift in the baseline noise was noted at $250 \mu \mathrm{M} \mathrm{L-trans-}$ PDC; this increase in baseline noise had a slower onset than the currents seen for the above compounds, and was completely blocked by $100 \mu \mathrm{M}$ APV. These results are consistent with recent reports (Isaacson and Nicoll, 1993; Sarantis et al., 1993) that L-trans-PDC induces an increase in tonic background NMDA receptor-mediated activity, probably via elevation of extracellular glutamate concentration (see below).

\section{$L$-trans-PDC depresses the amplitude of both NMDA and non-NMDA receptor-mediated components of the monosynaptically evoked EPSC}

In isolated pairs of hippocampal neurons, presynaptic stimulation of action potentials resulted in excitatory postsynaptic currents whose latencies, rise times, peak amplitude, and time to decay to one-half peak amplitude have been previously reported (Wilcox et al., in press). Stimulation of an action potential in the presynaptic cell results in an EPSC that contains both the fast non-NMDA receptor-mediated component and a slower rising and longer duration NMDA component (for review, see Collingridge and Lester, 1989). To determine the effects of uptake inhibition on monosynaptically evoked EPSCs, L-transPDC (100 and $250 \mu \mathrm{M}$ ) was perfused into the bathing solution. The extracellular bathing solution contained $4 \mathrm{mM} \mathrm{Ca}^{2+}$ to reduce the excitability of the neurons; $0 \mathrm{Mg}^{2+}$ and $10 \mu \mathrm{M}$ glycine were also used to allow full expression of the NMDA receptormediated component of the EPSC. L-Trans-PDC at $100 \mu \mathrm{M}$ reduced the peak non-NMDA component by $25.2 \pm 9.5 \%$ and the NMDA component, measured at $30-50 \mathrm{msec}$ after the stimulus artifact, by $34.7 \pm 11.7 \%$ (percentage change compared to control $\pm \mathrm{SD} ; n=6$ ). $\mathrm{L}$-Trans-PDC at $250 \mu \mathrm{M}$ reduced the peak non-NMDA and NMDA components by $39.8 \pm 14.7 \%$ and $50.39 \pm 18.9 \%$, respectively $(n=15)$ (Fig. $2 A, B)$. The percentage reduction in the non-NMDA and NMDA receptor-mediated components of the EPSCs are not significantly different (paired Student's $t$ test, $p>0.1$ ). At $100 \mu \mathrm{M}$, L-trans-PDC had no effect on the holding current; however, in 14 of the 15 cells recorded, perfusion of $250 \mu \mathrm{M}$ L-trans-PDC resulted in a small inward shift of the baseline current ( $\sim 20-40 \mathrm{pA})$. As shown in the next set of experiments, and also consistent with the findings of Sarantis et al. (1993) and Isaacson and Nicoll (1993), this inward current may be attributed to an increased tonic activation of 
A.

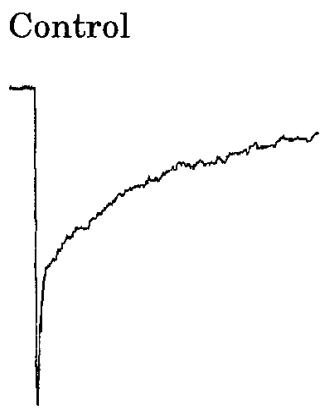

L-trans-PDC

Wash
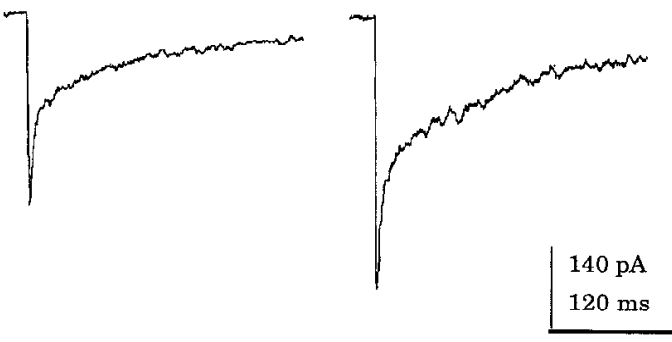

B.

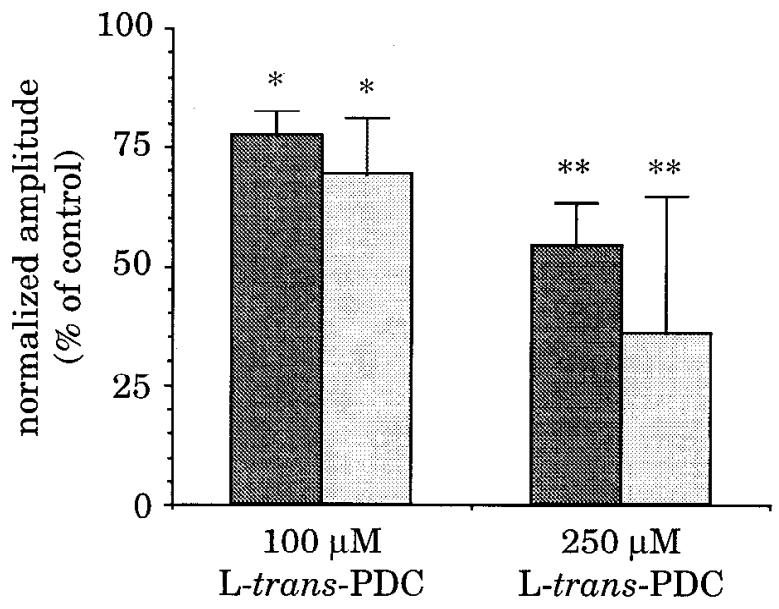

Figure 2. L-Trans-PDC decreases EPSC amplitude in isolated pairs of hippocampal neurons. $A$, EPSCs recorded at $-80 \mathrm{mV}\left(0 \mathrm{mM} \mathrm{Mg}^{2+}, 10 \mu \mathrm{M}\right.$ glycine) are reversibly decreased in amplitude upon perfusion of $250 \mu \mathrm{M}$ L-trans-PDC. $B$, Both the non-NMDA (dark bars) and NMDA (light bars) receptor-mediated components of the EPSC are significantly decreased by 100 $\mu \mathrm{M}$ and $250 \mu \mathrm{M}$ L-trans-PDC (paired Student's $t$ test, $p<0.05$ ). The NMDA component was measured at a single point for each cell at $30-50 \mathrm{msec}$ after the stimulus artifact. The percentage reduction in the non-NMDA and NMDA receptor-mediated components of the EPSCs are not significantly different (paired Student's $t$ test, $p>0.1$ ). Note: the time course of decay of the EPSC remained unchanged.
NMDA receptors by increased concentrations of extracellular glutamate.

The EPSCs were fitted with a sum of two exponential functions, indicating the initial rapid non-NMDA receptor-mediated component of the EPSC, followed by the slower decay of the NMDA receptor-mediated component. The decay time constants for EPSCs in 10 cells were not significantly changed in the presence of L-trans-PDC. Under control conditions, the fast component had a decay time constant of $5.8 \pm 5.8 \mathrm{msec}$, whereas the slow phase had a time constant of $89.9 \pm 28.0 \mathrm{msec}$. At $250 \mu \mathrm{M}$ L-trans-PDC, the dccay time constants were $5.4 \pm 4.5$ msec and $92.1 \pm 35.5 \mathrm{msec}$ for the fast phase and the slow phase, respectively. This finding is consistent with the reports that the decays of the non-NMDA and NMDA receptor-mediated components of the EPSC are determined by channel kinetics (Tang et al., 1989; Trussell and Fischbach, 1989; Hestrin et al., 1990; Lester et al., 1990) and not the clearance of transmitter from the synaptic cleft (Clements et al., 1992).

\section{$L$-trans- $P D C$ does not affect the peak amplitude of miniature EPSCS}

We then determined whether the depression of EPSC amplitude following application of L-trans-PDC was due to a changes in postsynaptic receptor sensitivity. Miniature postsynaptic currents in our hippocampal culture system have been previously characterized (Wilcox et al., in press), and are composed of both the fast non-NMD $\Lambda$ and slow NMDA receptor-mcdiatcd components under permissive conditions. The analysis of the frequency and the distribution of amplitudes of miniature synaptic currents can provide indications of changes in the sensitivity of postsynaptic receptors and/or of changes in the process of presynaptic transmitter release (del Castillo and Katz, 1954; Redman, 1990; Malgaroli and Tsien, 1992; Manabe et al., 1992). First, mEPSCs were recorded in high-density hippocampal cultures in the presence and absence of L-trans-PDC $(250 \mu \mathrm{M})$ under extracellular conditions where the NMDA receptors were blocked (1 $\mathrm{mM} \mathrm{Mg}^{2+}, 100 \mu \mathrm{M} \mathrm{APV},-80 \mathrm{mV}$ holding potential). No change in the amplitudes of the mEPSCs was observed upon application of L-trans-PDC $(n=8)$; cumulative frequency histograms of mEPSC amplitudes were not significantly changed (Kolmogorov-Smirnov statistic, $p>0.5$ ) (Fig. 3A) (van der Kloot, 1991). Thus, desensitization of postsynaptic non-NMDA receptors does not account for the depression of EPSC amplitude by L-trans-PDC. Figure $3 B$ provides a positive control for this analysis; a cumulative histogram plotting the relative frequency of mEPSC amplitudes at $-60 \mathrm{mV}$ and $-20 \mathrm{mV}$ shows a significant increase (Kolmogorov-Smirnov statistic, $p<0.001$ ) in the occurrence of larger-amplitude currents as the membrane potential increases and the driving force for the EPSC increases.

1S,3R-ACPD, a selective metabotropic receptor agonist, depresses the non-NMDA and NMDA receptor-mediated components of the EPSC; the depression is blocked by a metabotropic receptor antagonist $M C P G$

It has been demonstrated that activation of metabotropic glutamate receptors results in the depression of EPSC amplitude in various preparations (Forsythe and Clements, 1990; Baskys and Malenka, 1991; Desai and Conn, 1991; Pacelli and Kelso, 1991). To test whether the depression of EPSC amplitude by L-trans-PDC results from the activation of presynaptic auto- 
A.

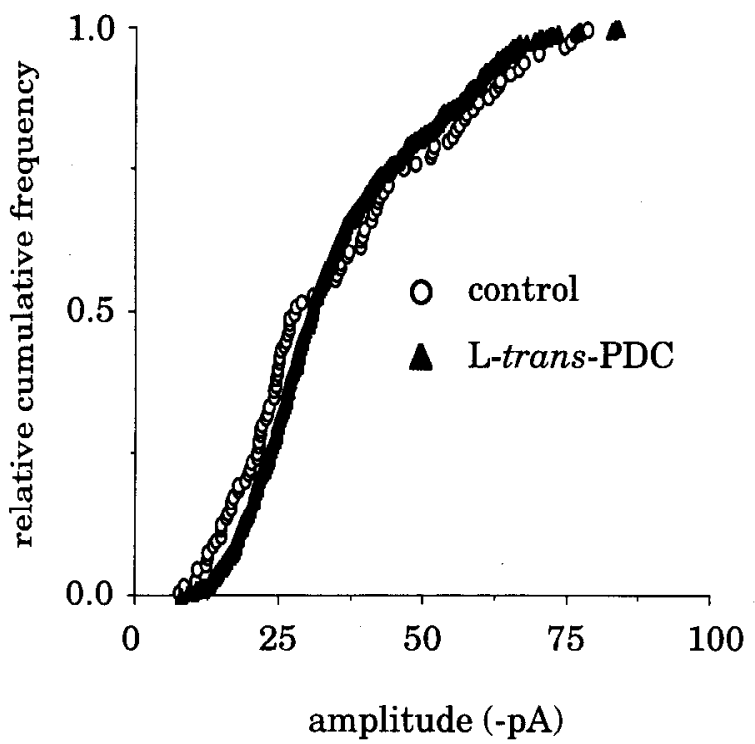

B.

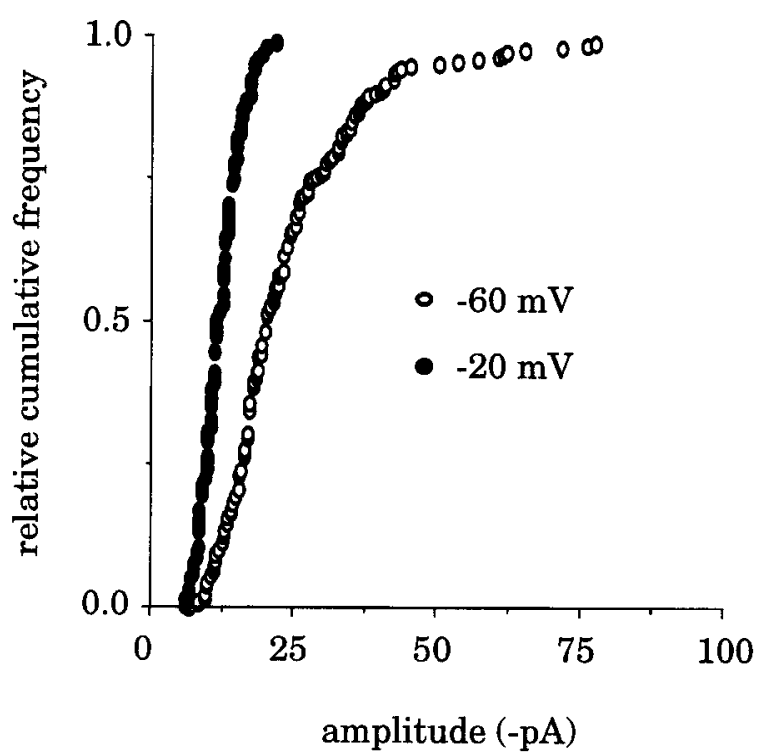

Figure 3. Cumulative frequency distributions of miniature EPSC amplitudes: mEPSC amplitude frequency distribution indicates a presynaptic mechanisms of action of L-trans-PDC. $A$, Bath application of $250 \mu \mathrm{M} \mathrm{L}$-trans-PDC does not have any significant effect on the distribution of mEPSC amplitudes (Kolmogorov-Smirnov statistic, $p>0.5$ ). B, To demonstrate the power of this analysis, a cumulative histogram plotting the relative frequency of mEPSC amplitudes at $-60 \mathrm{mV}$ and $-20 \mathrm{mV}$ shows a marked increase (Kolmogorov-Smirnov statistic, $p<0.001$ ) in the occurrence of larger-amplitude currents as the membrane potential increases and the driving force for the EPSC increases.

receptors, we first characterized the effects of the metabotropic agonist $1 S, 3 R$-ACPD and the antagonist $(R S)$ - $\alpha$-methyl-4-carboxyphenyl-glycine (MCPG) on monosynaptically evoked EPSCs. It has been recently reported that MCPG is a selective and competitive antagonist of $1 S, 3 R$-ACPD-mediated effects, as determined biochemically (Eaton et al., 1993; Littman and Robinson, 1994) and electrophysiologically (Bashir et al., 1993; Eaton et al., 1993).

$1 S, 3 R$-ACPD $(100 \mu \mathrm{M})$ did not induce any inward current when applied to the hippocampal neurons, but did decrease nonNMDA and NMDA receptor-mediated components of the EPSC by $48.0 \pm 23.9 \%$ and $49.9 \pm 20.4 \%$, respectively $(n=7$; all values represent percentage change compared to control $\pm \mathrm{SD}$ ) (Fig. 4A,C). MCPG (500 $\mu \mathrm{M}$ ) alone had no effect on EPSC amplitude $(n=5 ;-8.7 \pm 13 \%$ and $3.4 \pm 13 \%$, non-NMDA and NMDA components, respectively). MCPG at $500 \mu \mathrm{M}$ completely reversed the effects of $100 \mu \mathrm{M} 1 S, 3 R$-ACPD $(n=4 ;-14.5$ $\pm 16 \%$ and $-9.71 \pm 11 \%$, non-NMDA and NMDA components, respectively). There was no significant difference in the degree of depression induced by $1 S, 3 R$-ACPD between the nonNMDA and NMDA receptor-mediated components of the EPSC (paired Student's $t$ test, $p>0.1$ ).

$1 S, 3 R-A C P D$ and MCPG did not significantly affect the time course of decay of the EPSCs. Under control conditions, the time constants were $2.9 \pm 0.2 \mathrm{msec}$ and $55.4 \pm 6.6 \mathrm{msec}$ for the non-NMDA and NMDA receptor-mediated components, respectively; in the presence of $1 S, 3 R$-ACPD, the time constants were $3.1 \pm 0.2 \mathrm{msec}$ and $49.6 \pm 6.6 \mathrm{msec}$ (paired Student's $t$ test, $p=0.6$ and $p=0.4$ for the fast and slow phases, respectively). MCPG also had no effect on the time constants of the EPSCs. Note that the time constants for the slow component are faster in this set of experiments because glycine, an NMDA receptor coagonist, was omitted from the extracellular bath solution and the NMDA receptor-mediated component of the EPSC was only partially expressed.

\section{$M C P G$ blocks the depression of EPSC amplitude by $L$-trans- $P D C$}

We hypothesized that L-trans-PDC acts via a presynaptic mechanism to depress EPSC amplitude in monosynaptically connected pairs of hippocampal neurons. We therefore used MCPG to determine whether perfusion of L-trans-PDC results in the activation of metabotropic receptors. In eight of eight pairs tested, $500 \mu \mathrm{M}$ MCPG blocked the ability of $250 \mu \mathrm{M}$ L-transPDC to depress EPSC amplitude (Fig. 4B,C). L-Trans-PDC (250 $\mu \mathrm{M}$ ) depressed the non-NMDA and NMDA receptor-mediated components of the EPSC by $40.2 \pm 10.2 \%$ and $46.5 \pm 15.8 \%$, respectively (mean $\pm \mathrm{SD}$ for this subset of pairs). MCPG alone $(500 \mu \mathrm{M})$ had no significant effect $(-1.6 \pm 8.4 \%$ and $0.52 \pm$ $6.0 \%$; mean percentage change compared to control $\pm \mathrm{SD}$ ); MCPG fully reversed the effects of L-trans-PDC $(-1.6 \pm 9.3$ and $-12.4 \pm 11.7 \%$ ). There was no significant difference in the degree of depression of the non-NMDA and NMDA receptormediated components of the EPSC by L-trans-PDC (paired Student's $t$ test, $p=1.0$ ); however, there is a small significant difference between the degree of reversal by MCPG of the nonNMDA component and the NMDA component (paired Student's $t$ test, $p=0.04$ ). This may be explained by the differences in affinity of the non-NMDA and NMDA receptors for glutamate (Patneau and Mayer, 1990). CNQX at $10 \mu \mathrm{M}$ was used as a positive control to verify the flow of the perfusion system, and to demonstrate that the non-NMDA receptor-mediated component of the EPSC could be selectively blocked postsynaptically. The decay time constants for the fast and slow components of the EPSC were, as before, not significantly affected by either L-trans-PDC or MCPG (paired Student's $t$ test, $p>$ $0.5)$.

It is also important to note that in seven of the eight cells recorded, there was a significant inward shift of the baseline current upon perfusion of L-trans-PDC as seen previously, and 
A.

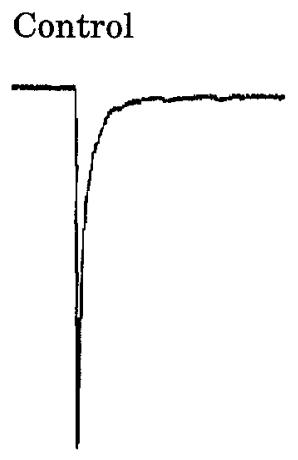

1S, 3R-ACPD

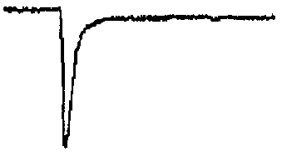

B.

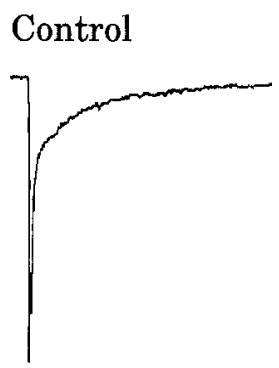

L-trans-PDC
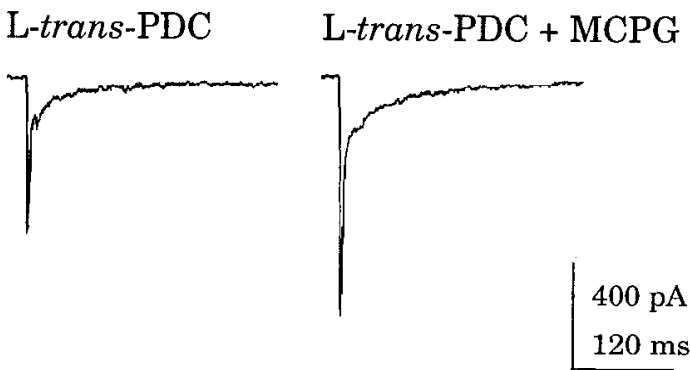

C.

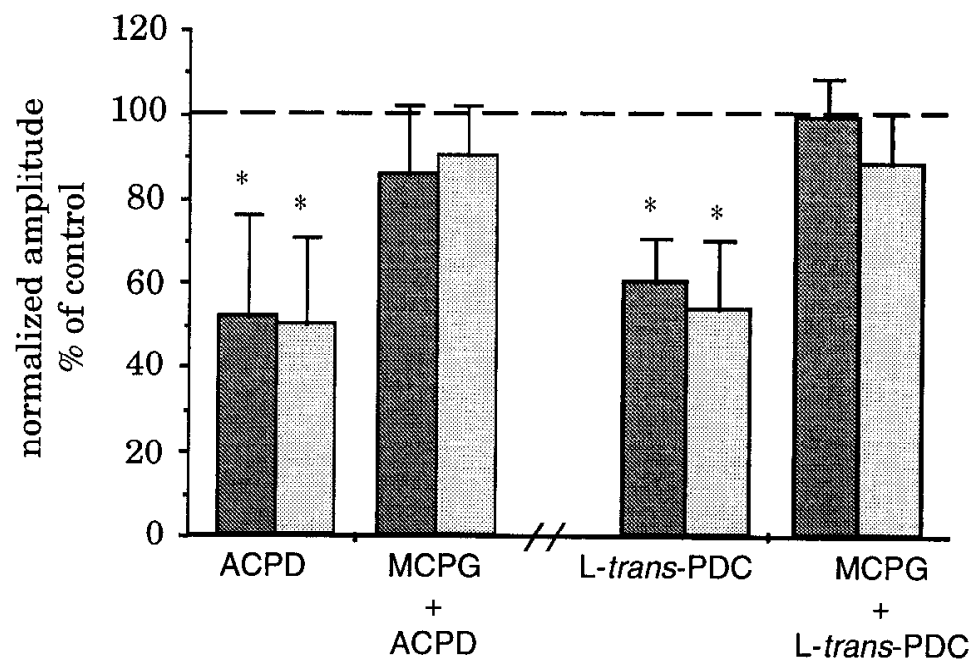

IS, 3R-ACPD + MCPG

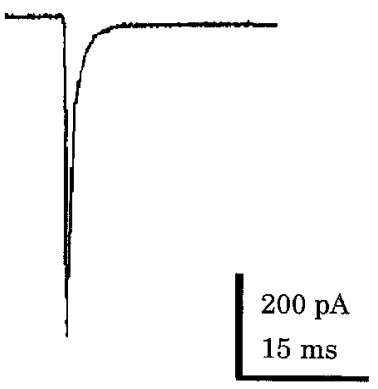

Figure 4. 1S,3R-ACPD and L-transPDC decrease EPSC amplitude, and are blocked by MCPG. $A, 1 S, 3 R-A C P D$, a metabotropic glutamate receptor agonist, at $100 \mu \mathrm{M}$ decreased the amplitude of the monosynaptically evoked EPSC at a holding potential of $-80 \mathrm{mV}(0$ $\mathrm{mM} \mathrm{Mg} \mathrm{Mg}^{2+}, 0 \mu \mathrm{M}$ glycine). As seen in the third trace, this depression was completely blocked by $500 \mu \mathrm{M}$ MCPG, a newly described metabotropic glutamate receptor antagonist. The time course of decay of the EPSCs remained unchanged. $B$, MCPG $(500 \mu \mathrm{M})$ fully reversed the effect of L-trans-PDC ( 250 $\mu \mathrm{M})$ at a holding potential of $-80 \mathrm{mV}$ $\left(0 \mathrm{~mm} \mathrm{Mg}{ }^{2+}, 10 \mu \mathrm{M}\right.$ glycine). The time course of decay of the EPSCs remained unchanged. $C$, Application of $1 S, 3 R$ ACPD $(100 \mu \mathrm{M})$ and L-trans-PDC (250 $\mu \mathrm{M})$ decreased the non-NMDA (dark bars) and NMDA (light bars) receptormediated components of the EPSC. MCPG at $500 \mu \mathrm{M}$ completely reversed the effects of $100 \mu \mathrm{M} 1 S, 3 R$-ACPD $(n$ $=4)$ and $250 \mu \mathrm{M} \mathrm{L}$-trans-PDC $(n=8)$. MCPG $(500 \mu \mathrm{M})$ alone had no effect on EPSC amplitude $(n=5)$. it remained unaffected by MCPG. Thus, to verify that the decrease in EPSC amplitude was not due to a postsynaptic effect of the increased baseline activity, conditions that isolated the non-NMDA component of the EPSC were used (1 mM extracellular $\mathrm{Mg}^{2+}, 2 \mathrm{mM} \mathrm{Ca}{ }^{2+}$ or $4 \mathrm{~mm}$ extracellular $\mathrm{Mg}^{2+}, 0 \mathrm{~mm}$ $\mathrm{Ca}^{2+}+100 \mu \mathrm{M}$ APV). The increase in baseline noise did not occur under these conditions, indicating that the inward shift of the current was due to tonic activation of NMDA receptors. The peak amplitude of the isolated non-NMDA component EPSC was still decreased upon perfusion with $250 \mu \mathrm{M}$ L-transPDC $\left(36.5 \pm 22 \%, n=4\right.$ in the presence of $1 \mathrm{mM} \mathrm{Mg}^{2+} ; 48.8$ $+26 \%, n=4$ in the presence of APV) and was completely blocked by $500 \mu \mathrm{M}$ MCPG in all the cells tested $(n=5)$.
Depression of EPSC amplitude by $2 \mu \mathrm{M} L$-glutamate is blocked by MCPG; mimicry of the actions of $L$-trans-PDC

Forsythe and Clements (1990) have previously reported that very low concentrations of glutamate decrease EPSC amplitude in cultured mouse hippocampal neurons via a presynaptic mechanism. We proposed that L-trans-PDC indirectly caused an activation of metabotropic receptors by an accumulation of extracellular glutamate due to uptake inhibition. Therefore, $2 \mu \mathrm{M}$ glutamate was added to the bath while recording from pairs of hippocampal neurons in order to determine if this could mimic the effects of L-trans-PDC on EPSC amplitude and baseline noise. Perfusion of $2 \mu \mathrm{M}$ glutamate resulted in an increase in 
tonic NMDA receptor-mediated activity, as indicated by APV sensitivity of the increase in baseline noise $(n=3)$. Glutamate at $2 \mu \mathrm{M}$ also reversibly depressed both components of the EPSC amplitude $(36.7 \pm 24 \%$ and $44.6 \pm 29 \% ; n=5$; all values represent percentage change compared to control). MCPG, the metabotropic receptor antagonist, at $500 \mu \mathrm{M}$ had no effect on EPSC amplitude when applied alone, but blocked the effects of $2 \mu \mathrm{M}$ glutamate $(-4.7 \pm 25 \%$ and $1.4 \pm 15 \%)$. There was no significant change in the time course of decay upon application of $2 \mu \mathrm{M}$ glutamate (control, $3.12 \pm 0.6 \mathrm{msec}$ and $115.23 \pm 9.77$ msec; glutamate, $3.0 \pm 0.5 \mathrm{msec}$ and $114.3 \pm 16.2 \mathrm{msec}$ for the fast and slow components, respectively). Thus, these observed effects of very low concentrations of glutamate on excitatory synaptic transmission in our culture system are consistent with the hypothesis that the effects of L-trans-PDC are due to the accumulation of extracellular glutamate which then activates presynaptic metabotropic receptors.

\section{Discussion}

Our data indicate that inhibition of glutamate uptake by L-transPDC causes a depression of the amplitude of evoked EPSCs with no change in their durations. We propose that this occurs via a presynaptic mechanism, possibly due to glutamate accumulation in extracellular spaces activating metabotropic receptors.

L-Trans-PDC potently and selectively inhibited the reuptake of glutamate with an $\mathrm{IC}_{50}$ of $26 \mu \mathrm{M}$ in high density cultures of hippocampal neurons. However, unlike several other glutamate transport inhibitors, L-trans-PDC at concentrations up to $1 \mathrm{~mm}$ did not directly activate postsynaptic ionotropic EAA receptors. On the other hand, each of the other previously used glutamate uptake inhibitors (DHK, THA, and $\mathrm{L}-\mathrm{A} \beta \mathrm{H}$ ) did activate EAA receptors when applied directly onto hippocampal neurons monitored in the whole-cell voltage-clamp mode. Direct agonist action of uptake inhibitors could alter the postsynaptic response to both exogenously applied or synaptically released ncurotransmitter, either via enhanced activation of postsynaptic currents or desensitization of postsynaptic receptors.

Neurons that were fairly isolated from neighboring neurons and dense glia were used to minimize the effects of local glutamate release in the presence of these compounds. The currents induced by all the compounds, including very high concentrations of L-trans-PDC, were blocked by the EAA receptor antagonists APV and CNQX. The currents induced by application of DHK, THA, and $\mathrm{L}-\mathrm{A} \beta \mathrm{H}$ (at concentrations used to inhibit glutamate uptake) were rapid in onset and identical in shape and time course to the response of the neurons to direct puffer application of glutamate. Unusually high concentrations of L-trans-PDC were needed to induce a similar inward current in response to direct application via the puffers. Compounds that interact with the glutamate transporter can serve as substrates, and thcreby causc a hctcrocxchange, resulting in release of cytoplasmic glutamate (Attwell et al., 1993). Therefore, it is possible that the uptake inhibitors DHK, THA, and L-A $\beta \mathrm{H}$ cause a rapid inward current by direct activation of postsynaptic receptors, by indirect release of glutamate via rapid heteroexchange with cytosolic glutamate that activates these receptors, or by a combination of these processes. Our data favor direct activation of postsynaptic receptors.

It is important to recognize that the lower concentrations of L-trans-PDC that were used in the EPSC experiments resulted in a slow increase in baseline noise that could be blocked by the
NMDA receptor antagonist APV, which was very different from the fast inward current induced by the uptake inhibitors discussed above. The activation of NMDA receptors could result from the direct activation by L-trans-PDC, or from an indirect consequence of the accumulation of extracellular glutamate following uptake inhibition by L-trans-PDC. As with the puffer experiments, the increase in baseline noise following bath application of L-trans-PDC occurred gradually over several seconds, consistent with an increase in extracellular glutamate rather than a direct action at the NMDA receptors. In fact, when we mimicked this change in background noise by perfusion of $2 \mu \mathrm{M}$ glutamate, the onset of the increase in baseline noise was faster than the time course of this response to L-trans-PDC in all cells tested, indicating that slow accumulation of extracellular glutamate concentrations may account for the increase in baseline noise.

Sarantis et al. (1993) also reported that L-trans-PDC caused a substantial inward current and increase in baseline noise that could be completely blocked by the NMDA antagonist APV. Isaacson and Nicoll (1993) concluded that the current induced by L-trans-PDC is due to an increase in ambient concentrations of glutamate rather than direct activation of NMDA receptors; channel activity in outside-out patches was used as an indicator for glutamate presence in the extracellular space following application of L-trans-PDC to a hippocampal slice preparation.

\section{Depression of excitatory synaptic transmission by}

$L$-trans- $P D C$ is via a presynaptic mechanism

Several lines of evidence suggest that L-trans-PDC results in a depression of EPSC amplitude via a presynaptic mechanism. First, both the non-NMDA and NMDA components of the EPSCs were depressed to approximately the same degree upon perfusion of $\mathbf{L}$-trans-PDC. A decrease in the probability of presynaptic release readily explains a parallel decrease in both components of the evoked EPSC. Second, mEPSC amplitude distribution was unchanged upon application of L-trans-PDC, indicating no change in receptor sensitivity and therefore demonstrating that a presynaptic mechanism mediates the decrease in EPSC amplitude. Desensitization of non-NMDA receptors would have been detected as a shift in the amplitude distribution of mEPSCs, and thus does not account for the decrease in the EPSC amplitude. Third, the demonstration that the novel antagonist MCPG not only blocked the ability of the selective metabotropic agonist $1 S, 3 R$-ACPD but also L-trans-PDC to depress EPSC amplitude indicates that activation of presynaptic metabotropic receptors is involved.

We propose that L-trans-PDC causes an accumulation of glutamate in the extrasynaptic space, which results in activation of presynaptic metabotropic receptors. This hypothesis was tested indirectly by perfusing very low concentrations of L-glutamate to mimic the effects of L-trans-PDC on EPSCs. Like L-transPDC, $2 \mu_{M}$ glutamate decreased both the non-NMDA and NMDA receptor-mediated components of the EPSC; this effect was blocked by the metabotropic receptor antagonist MCPG. As was observed for L-trans-PDC, glutamate caused an increase in the baseline noise which was abolished in APV, indicating that increased tonic activation of NMDA receptors may serve as an indicator of increased ambient levels of glutamate (Sah et al., 1989). By contrast, isolated pairs of inhibitory neurons in our very-low-density cultures may not be in contact with a nearby source of glutamate release and may be expected to not show the increased membrane noise with L-trans-PDC. Indeed, 
only five of 13 neurons in inhibitory pairs tested exhibited an increase in baseline noise upon application of $\mathrm{L}$-trans-PDC (Maki, Robinson, and Dichter, unpublished observation), despite all inhibitory hippocampal neurons in our cultures having functional NMDA receptors. Thus, at least in these neurons, L-transPDC does not directly activate NMDA receptors.

Our data cannot conclusively rule out the possibility that $\mathrm{L}$-trans-PDC is acting directly on metabotropic receptors. Experiments aimed at determining whether the effects of L-transPDC are due to direct activation of metabotropic receptors cannot be done in an intact system where sources of glutamate release, glutamate transporters, and metabotropic receptors exist in proximity to cach other (c.g., ccll culture, slice). It would be necessary to completely isolate the process of glutamate uptake from the activation of EAA receptors to assess systematically whether L-trans-PDC is acting directly or indirectly via increased glutamate concentration. Indirect consequences of local accumulation of glutamate following uptake inhibition will, in a physiologic environment, result in responses that are not able to be distinguished from direct agonist actions of the uptake inhibitor. In our hippocampal cultures, the actions of L-transPDC on any cellular effector system (e.g., EPSCs, PI hydrolysis, cAMP, $\mathrm{Ca}^{2+}$ signals, etc.) cannot be conclusively deemed direct or indirect. It seems clear that L-trans-PDC acts presynaptically to depress excitatory synaptic transmission. In addition, the data indicating that $\mathbf{L}$-trans-PDC induces gradual increases in tonic NMDA receptor activation following uptake inhibition and that this effect is mimicked by low concentrations of glutamate, and the preliminary data in inhibitory paircd recordings, all suggest the hypothesis that $\mathbf{L}$-trans-PDC acts indirectly via an accumulation of extracellular glutamate to activate metabotropic receptors.

The depression of evoked EPSCs between hippocampal neurons in culture induced by L-trans-PDC is robust and occurred in all cells tested. However, Sarantis et al. (1993) and Isaacson and Nicoll (1993) using an more intact system of hippocampal slices did not observe consistent depression of EPSC amplitude. Negative feedback of increased ambient glutamate may not play as pivotal a role in a more complex tissue as it does in culture, possibly due to differences in accessibility of presynaptic autoreceptors. Earlier experiments with GABA uptake inhibitors demonstrated a decrease in the amplitude of spontaneous IPSCs in cultured hippocampal neurons, presumably by activation of presynaptic $\mathrm{GABA}_{\mathrm{B}}$ receptors (Oh and Dichter, 1994). However, similar experiments in the slice preparation demonstrated enhancement of IPSCs by inhibition of GABA uptake, presumably by activation of postsynaptic $\mathrm{GABA}_{\mathrm{B}}$ receptors (Thompson and Gahwiler, 1992; Isaacson et al., 1993) (which do not appear to be expressed in neurons in dissociated cell cultures). Thus, the relative roles of different receptor activation patterns for pre- and postsynaptic receptors in both the GABA-mediated inhibitory system and the EAA system may differ in different preparations of CNS tissues and between different regions in the intact CNS. Consequently, the effects of drugs which act as uptake inhibitors may be hard to predict at the level of the whole organism (Oh and Dichter, 1994).

It is interesting to note that desensitization of the non-NMDA receptors did not appear to occur under conditions where the ambient concentrations of glutamate were presumably increased (Tang et al., 1989; Trussel and Fischbach, 1990). It may be that the non-NMDA receptors at synaptic endings are somcwhat "sheltered" from the increased glutamate concentrations. Al- ternatively, data from single-channel recordings may not directly apply to the receptors as they are anchored in the membrane (see Frosch et al., 1992). It seems clear, however, that metabotropic glutamate receptors found on presynaptic terminals are affected by the increased ambient glutamate (Forsythe and Clements, 1990). In addition, the NMDA rcceptors (synaptic or extrasynaptic) were sensitive to the changes in ambient glutamate concentrations, as shown by the increase in baseline noise upon application of $2 \mu \mathrm{M}$ glutamate or the uptake inhibitor L-trans-PDC. Sah et al. (1989) have also shown that NMDA receptors may be tonically activated by ambient glutamate. Thus, the NMDA receptor-mediated noise could serve as an indicator of slight increases in ambient glutamate concentrations.

The experiments reported here support a model whereby inhibition of glutamate uptake appears to cause an increase in ambient glutamate concentrations, which in turn activates presynaptic metabotropic receptors, leading to a decrease in synaptic transmission. Thus, alterations in the clearance of glutamate from the extracellular space may have significant consequences for changes in synaptic efficacy.

\section{References}

Attwell D, Barbour B, Szatkowski M (1993) Nonvesicular release of neurotransmitter. Neuron 11:401-407.

Bashir ZI, Borlotto ZA, Davies CH, Berretta N, Irving AJ, Seal AJ, Henley JM, Jane DE, Watkins JC, Collingridge GL (1993) Induction of LTP in the hippocampus needs synaptic activation of glutamate metabotropic receptors. Nature 363:347-350.

Baskys A, Malenka RC (1991) Agonists at metabotropic glutamate receptors presynaptically inhibit EPSCs in neonatal rat hippocampus. J Physiol (Lond) 444:687-701.

Bridges RJ, Stanley MS, Anderson MW, Cotman CW, Chamberlin AR (1991) Conformationally defined neurotransmitter analogs. Selective inhibition of glutamate uptake by one pyrrolidine-2,4-dicarboxylate diastereomer. J Med Chem 34:717-725.

Brodin L, Tossman U, Ohta Y, Ungerstedt U, Grillner S (1988) The effect of an uptake inhibitor (dihydrokainate) on endogenous excitatory amino acids in the lamprey spinal cord as revealed by microdialysis. Brain Res 458:166-169.

Buchhalter JR, Dichter M (1991) Electrophysiological comparison of pyramidal and stellate non-pyramidal neurons in dissociated cell culture of rat hippocampus. Brain Res Bull 26:333-338.

Choi DW, Fischbach GD (1981) GABA conductance of chick spinal cord and dorsal root ganglion neurons in cell culture. J Neurophysiol 45:605-620.

Clements JD, Lester RAJ, Tong G, Jahr CE, Westbrook GL (1992) The time course of glutamate in the synaptic cleft. Science 258:14981501.

Collingridge G, Lester RAJ (1989) Excitatory amino acid receptors in the vertebrate central nervous system. Pharmacol Rev 40:143-210.

del Castillo J, Katz B (1954) Statistical factors involved in neuromuscular facilitation and depression. J Physiol (Lond) 124:574-585.

Desai MA, Conn PJ (1992) Excitatory effects of ACPD receptor activation in the hippocampus are mediated by direct effects on pyramidal cells and blockade of synaptic inhibition. J Neurophysiol 66: $40-52$.

Eaton SA, Jane DE, Jones PLStJ, Porter RHP, Pook PC-K, Sunter DC, Udarhelyi PM, Roberts PJ, Salt TE, Watkins JC (1993) Competitive antagonism at metabotropic glutamate receptors by $(S)$-4-carboxyphenylglycine and $(R S)$ - $\alpha$-methyl-4-carboxyphenylglycine. Eur J Pharmacol 244:195-197.

Forsythe JD, Clements JD (1990) Presynaptic glutamate receptors depress excitatory monosynaptic transmission between mouse hippocampal neurons. J Physiol (Lond) 429:1-16.

Frosch M, Lipton S, Dichter M (1992) Desensitization of GABAactivated currents and channels in cultured cortical neurons. J Neurosci 12:3042-3053.

Hamill OP, Marty A, Neher E, Sakmann B, Sigworth FJ (1981) Improved patch-clamp techniques for high-resolution current recording 
from cells and cell-free membrane patches. Pfluegers Arch 391:85100.

Hestrin S, Sah P, Nicoll RA (1990) Mechanisms generating the time course of dual component excitatory synaptic currents recorded in hippocampal slices. Neuron 5:247-253.

Isaacson JS, Nicoll RA (1993) The uptake inhibitor L-trans-PDC enhances responses to glutamate but fails to alter the kinetics of excitatory synaptic currents in the hippocampus. J Neurophysiol 70:21872191.

Isaacson JS, Solis JM, Nicoll RA (1993) Local and diffuse synaptic actions of GABA in the hippocampus. Neuron 10:165-175.

Johnston GAR, Lodge D, Bornstein JC, Curtis DR (1980) Potentiation of L-glutamatc and L-aspartate excitation of cat spinal neurons by stereoisomers of threo-3-hydroxyaspartate. J Neurochem 34:241-243.

Kanai Y, Smith CP, Hediger MA (1993) The elusive transporters with a high affinity for glutamate. Trends Neurosci 16:365-370.

Kanner BI (1993) Glutamate transporters from brain. A novel neurotransmitter transporter family. FEBS Lett 325:95-99.

Lester RA, Clements JD, Westbrook GL, Jahr CE (1990) Channel kinetics determine the time course of NMDA receptor-mediated synaptic currents. Nature 346:565-567.

Littman L, Robinson MB (1994) The effects of L-glutamate and trans (士)-1-amino-1,3-cyclopentane dicarboxylate on phosphoinositide hydrolysis can be pharmacologically differentiated. J Neurochem, in press.

Littman L, Munir M, Flagg SD, Robinson MB (1992) Multiple mechanisms for inhibition of cxcitatory amino acid rcceptors coupled to phosphoinositide hydrolysis. J Neurochem 59:1893-1904.

Lodge D, Johnston GAR, Curtis DR, Bornstein JL (1979) Kainate neurotoxicity and glutamate inactivation. Neurosci Lett 14:343-348.

Lodge D, Curtis DR, Johnston GAR, Bornstein JL (1980) In vivo inactivation of quisqualate: studies in the cat spinal cord. Brain Res 182:491-495.

Malgaroli A, Tsien RW (1992) Glutamate-induced long-term potentiation of the frequency of miniature synaptic currents in cultured hippocampal neurons. Nature 357:134-139.

Manabe T, Renner P, Nicoll RA (1992) Postsynaptic contribution to long-term potentiation revealed by the analysis of miniature synaptic currents. Nature 355:50-55.

Mennerick S, Zorumski CF (1994) Glial contribution to excitatory neurotransmission in cultured hippocampal cells. Nature 368:59-62

Oh DJ, Dichter MA (1994) Effect of a GABA uptake inhibitory NNC711 on spontaneous postsynaptic currents in cultured rat hippocampal neurons-implications for antiepileptic drug development. Epilepsia $35: 426-430$.
Pacelli GJ, Kelso SR (1991) Trans-ACPD reduces multiple components of synaptic transmission in the rat hippocampus. Neurosci Lett 132:267-269.

Patneau DK, Mayer ML (1990) Structure-activity relationship for amino acid transmitter candidates acting at $N$-methyl-D-aspartate and quisqualate receptors. J Neurosci 10:2385-2399.

Redman S (1990) Quantal analysis of synaptic potentials in neurons of the central nervous system. Physiol Rev 70:165-198.

Robinson MB, Hunter-Ensor M, Sinor JD (1.991) Pharmacologically distinct sodium-dependent $\mathrm{L}_{-}\left[{ }^{3} \mathrm{H}\right]$ glutamate transport processes in rat brain. Brain Res 544:196-202.

Robinson MB, Sinor JD, Dowd LA, Kerwin JF (1993) Subtypes of sodium-dependent $\mathrm{L}-\left[{ }^{3} \mathrm{H}\right]$ glutamate transport activity: pharmacologic specificity and regulation by sodium and potassium. $J$ Neurochem 60:167-179.

Sah P, Hestrin S, Nicoll RA (1989) Tonic activation of NMDA receptors by ambient glutamate enhances excitability of neurons. Science 246:815-818.

Sarantis M, Ballerini L, Miller B, Silver RA, Edwards M, Attwell D (1993) Glutamate uptake from the synaptic cleft does not shape the decay of the non-NMDA component of the synaptic current. Neuron $11: 541-549$

Saweda S, Higashima M, Yamamoto C (1985) Inhibitors of highaffinity uptake augment depolarizations of hippocampal neurons induced by glutamate, kainate and related compounds. Exp Brain Res 60:323-329.

Tang CM, Dichter M, Morad M (1989) Quisqualate activates a rapidly inactivating high conductance ionic channel in hippocampal neurons. Science 243:1474-1477.

Thompson SM, Gahwiler BH (1992) Effects of the GABA uptake inhibitor tiagabine on inhibitory synaptic potentials in rat hippocampal slice cultures. J Neurophysiol 67:1698-1701

Trussell LO, Fischbach GD (1989) Glutamate receptor desensitization and its role in synaptic transmission. Neuron 3:209-218.

van der Kloot W (1991) The regulation of quantal size. Prog Neurobio 36:93-130.

Wilcox KS, Dichter MA (1994) Paired pulse depression in cultured hippocampal neurons is due to a presynaptic mechanism independent of $\mathrm{GABA}_{\mathrm{B}}$ autoreceptor activation. J Neurosci 14:1775-1788.

Wilcox KS, Buchhalter JR, Dichter MA (in press) Properties of inhibitory and excitatory synapses between hippocampal ncurons in very low density cultures. Synapse, in press. 